\title{
From online cart to plate: What Amazon's retail domination means for the future of food
}

\author{
Carly Livingstone ${ }^{\mathrm{a} *}$ and Irena Knezevic ${ }^{\mathrm{b}}$ \\ Carleton University
}

Submitted December 11, 2019 / Revised March 16 and April 13, 2020 / Accepted April 13, 2020 /

Published online September 1, 2020

Citation: Livingstone, C., \& Knezevic, I. (2020). From online cart to plate: What Amazon's retail

domination means for the future of food. Journal of Agriculture, Food Systems, and Community

Development, 9(4), 311-329. https://doi.org/10.5304/jafscd.2020.094.017

Copyright (C) 2020 by the Authors. Published by the Lyson Center for Civic Agriculture and Food Systems. Open access under CC-BY license.

\begin{abstract}
Amazon's 2017 purchase of Whole Foods Market seemed to suddenly make this commercial giant a notable player in food retail. However, as we demonstrate below, this development was neither sudden nor surprising. Amazon's business strategy has paved the way both for this acquisition, and for the other surreptitious ways in which it is chipping its way into food retail. We argue that these developments are motivated by Amazon's goal of becoming a one-stop-shop for all consumer goods for as many customers as possible, which would in turn allow Amazon to expand as the key global
\end{abstract}

a* Corresponding author: Carly Livingstone, MA Communication, Specialization in Data Science, School of Journalism and Communication, Carleton University; 1125 Colonel By Drive; Ottawa, ON K1S 5B6 Canada; +1-587-783-9056; carlylivingstone@.cmail.carleton.ca

${ }^{b}$ Dr. Irena Knezevic, Associate Professor, School of Journalism and Communication, Carleton University; 1125 Colonel By Drive; Ottawa ON K1S 5B6 Canada; +1-613-520-2600 ext. 4121; Irena.Knezevic@,carleton.ca broker for consumer data. Although Amazon's tactics have little to do with food itself, the implications to food retail and more generally to food systems around the globe could be momentous.

\section{Keywords}

Amazon, Big Data, Market Concentration, Whole Foods Market, Datafication, Food Retail

\section{Introduction}

When Amazon purchased Whole Foods Market (WFM) in 2017, its entry into the fresh food sector and the addition of physical locations received much media attention. Forbes magazine pointed to Amazon's wealth of data as the key tool for industry disruption, noting "Amazon is using Data

\section{Note on COVID-19}

This research was conducted before the 2020 pandemic. The implications of our findings are nevertheless still relevant, and perhaps even more significant now that more consumers appear to be using online platforms to shop for food. 
to reverse-engineer retail" (Aziza, 2017, para. 3). The visibility of this purchase made it seem like Amazon was shifting gears, but a closer look at the company strategy over the years reveals that this purchase was rather unsurprising. In this paper we explore Amazon's foray into food retail to ask: What drove Amazon to move into food retail and what steps has Amazon taken to enter and expand into this market? What is enabling it to succeed in monopolizing purchasing habits, and what are the potential implications if the power of the world's largest internet company is not checked? We argue that the complex interplay of technology, data capabilities, and lax regulatory regimes are both driving and enabling Amazon to vie for consolidated control of food retail. We observe, however, that this control is not born of Amazon's desire to dominate food retail. Instead, food retail is merely collateral damage in Amazon's larger strategy of stealth.

We describe the context of digital retail and digital economies of scale, and then trace Amazon's growth and foray into food retail. We argue that Amazon's overall strategy was already wellsuited to the risky business of online groceries. We suggest that this strategy, combined with the current regulatory environment, is allowing Amazon to become the sole retailer a customer would need for all their consumer goods. Next, we discuss potential implications of Amazon's strategy for food retail, and more broadly for food systems. We conclude that Amazon's development is troubling, as the consequences in this sector may be much more far-reaching than in other retail sectors.

\section{Background and Literature Review}

Political economists have been fascinated by Amazon as the embodiment of market concentration and datafication of the consumer (Culpepper \& Thelen, 2019; Mosco, 2017; Srnicek, 2017). Political economy is "the study of the social relations, particularly the power relations, that mutually constitute the production, distribution, and consumption of resources, including communication resources" (Mosco, 2009, p. 2). Political economists ask, "how are power and wealth related and how are these in turn connected to cultural and social life?" (Mosco, 2009, p. 4). We approach our analysis from the political economy perspective and draw on this tradition's key concepts of concentration and economies of scale.

\section{Concentration}

Concentration refers to "the composition of a given market and especially its potential impacts on competition" (Howard, 2016, p. 3). Concentration is a spectrum. At one end are freely competitive, fragmented or unconcentrated markets that function on the basis of supply and demand, curbing any one company's ability to raise prices; at the other end are monopolies and oligopolies, in which a single firm or handful of firms dominate, leaving consumers at the behest of the few corporations that have the power to set and control prices (Howard, 2016).

Regardless of industry, political economists agree that shifting away from competitive markets towards consolidation has political and economic implications. Concentrated power means fewer people are involved in decision-making, particularly around "what is produced, how it is produced, and who has access to these products" (Howard, 2016, p. 5). With larger firms emerging out of mergers and acquisitions, other firms struggle to enter the market; if they do enter the market, prices are still set by larger firms that then obtain greater percentages of the profits (Howard, 2016). As becomes apparent below, Amazon's size and scope call for an analysis through the lens of concentration, casting doubt on e-commerce's ability to facilitate free market competition.

Studies of power in the agri-food sector offer ample critique of concentration, and readers of this journal will be familiar with at least some of them. Phil Howard has examined concentration extensively (see Howard, 2014, 2015, 2016, 2018, 2019). Various authors have discussed the "hourglass" system, where multiple producers and consumers are connected through a handful of retail companies and agricultural suppliers who control food economy and governance. This results in barriersto-entry for small- and medium-sized businesses, and significant economic and cultural threats to both consumers and producers around the globe (Kneen, 1993; Lang \& Heasman, 2003; Patel, 2007). 
Economies of Scale and Digital Economies of Scale

Political economists dispute mainstream economy's stance that concentration enables firms to take advantage of economies of scale. While "consumers are often claimed to benefit from synergies and lower transaction costs that are expected to result from mergers and acquisitions" (Farrell \& Shapiro, 2001, cited in Howard, 2016, p. 8), there was traditionally little evidence that increasingly large and complex organizations experience an increase in efficiency (Howard, 2016). The web-commerce boom of the 1990s and 2000s added the question of whether the original tenets of economics and political economy would hold true in the digital age. Vincent Mosco asked: "are the forces of new communication and technology so revolutionary that they are bringing about a radical restructuring and that will lead to the transformation or even the dissolution of capitalism?" (Mosco, 2009, p. 3). Early e-commerce scholars viewed e-commerce as a "paradigm shift": a "disruptive innovation ... radically changing the traditional way of doing business," and saw it as operating "under totally different principles and work rules in the digital economy" (Lee, 2001, p. 349).

Robert McChesney (2013) argued to the contrary-that internet giants were, ultimately, like other traditional commercial entities and that the internet would hardly usher in a new economic frontier. Indeed, the internet seems to solidify topheavy corporate concentration that works systemically to create an anticompetitive environment (Winseck, 2016).

Echoing McChesney, Hindman argues that firms like Amazon take advantage of digital economies of scale that enable them to concentrate traffic (2018). The internet "provides economies of scale in 'stickiness"'-a term Hindman uses to refer to the tactics internet firms utilize to "attract and keep audiences" (p. 16). Sites, as they grow, become progressively cheaper per user: more visitors allow for expansion, attracting even more visitors, and building visitor loyalty over time. Amazon's survival relies on stickiness to ensure that users come back to the site for all of their purchasing needs. Hindman focuses on media firms and draws attention to six aspects of digital economies of scale, including network effects, architectural advantages, design advantages, advertising and branding, user learning, and path dependence and the dynamics of lock-in, arguing that each of these factors "tilt the playing field" towards already powerful internet firms. Ultimately, he argues that "large media firms still dominate, for reasons economists will find both novel and familiar" (p. 5). As our analysis shows, these dynamics prove useful in understanding Amazon's business strategy.

\section{Food Retail and E-Commerce}

Food retail largely evaded the e-commerce takeover that transformed myriad industries in the 1990s. While electronics, books and other products transitioned to the "new" economy of electronic and "frictionless" transactions that minimized costs and promised a "better way of doing business for both retailers and consumers" (Morganosky \& Cude, 2002, p. 451), the grocery sector resisted this trend. The logistics of delivering fresh produce are substantially more complex, as the challenge of long-distance delivery of low profit-margin products is further complicated by the need for physical infrastructure such as warehousing, refrigeration and distribution centers, and strict quality and safety regulations (de Koster, 2002; de Koster \& Neuteboom, 2001). E-grocers need to deliver from sites close to consumers, and sparsely populated areas pose problems for all retailers (Williams, 2017). Combined with the challenge of "consumer trust in the context of online purchasing," (Morganosky \& Cude, 2002, p. 452) and a preference for brick-and-mortar grocery stores, food retail became the stubborn last frontier (Williams, 2017) and "the toughest nut in ecommerce" (Jones, 2018, para. 1).

In 2018, 30 percent of Americans purchased groceries online (Nielsen, 2018a, para. 1), up from 13 percent in 2015 (FMI), and of all online purchases made by Americans between 2017-2018, food and beverage sales made up 13 percent (Nielsen, 2018a, para. 4). In the U.S. alone, "fresh and perishable foods generated brick-and-mortar sales of more than US $\$ 177$ billion in 2017-18" (Nielsen, 2018a, para. 5). Across the "fast-moving" brick-and-mortar retail landscape of quickly-sold, low-cost consumer goods, "fresh categories have 
driven nearly $49 \%$ of the dollar growth" (Nielsen, 2018a, para. 5). The percentage of Americans purchasing their groceries online is expected to grow to 70 percent in the next decade ("Why ECommerce Shouldn't," 2018, para. 1). Amazon is in the lead with 18 percent of the U.S. online grocery sales "marking the largest share of any single retailer and doubling that of its closest competitor, Walmart Inc" (One Click Retail, 2017 cited in Taylor, 2018, para. 2). Globally, the most significant e-commerce activity growth includes packaged and fresh groceries (Nielsen, 2018b). With online grocery sales set to reach US $\$ 100$ billion by 2025 (Danziger, 2018), it is a race to innovate and capture consumer purchasing power.

Amazon's Transition into the Food Market

In 2017, Amazon was the first search for 44 percent of all global e-retail purchases (Khan, 2016). It is unclear how this translates specifically to online food purchases, but Amazon is working quickly and quietly to replace traditional grocery chains and supermarkets. The largest global internet company began eyeing food retail in 1999 (Figure 1), entering this sector in earnest in 2013, promising to upend food retail with e-commerce (Barr, 2013). In 1999, Amazon paid US $\$ 42.5$ million to acquire a 35 percent stake in HomeGrocer. com, the first fully integrated internet grocery shopping and home delivery service (Amazon, 1999). Amazon Gourmet Food Store launched in 2003, offering Amazon shoppers "gourmet" food, limited to dry goods and non-perishables (Amazon, 2003). In 2005, Amazon Services Europe Inc. announced an "alliance" with Marks \& Spencer, the UK's leading retailer of clothes, food, and

Figure 1. Amazon's Transition into Food Retail, 1996-2020

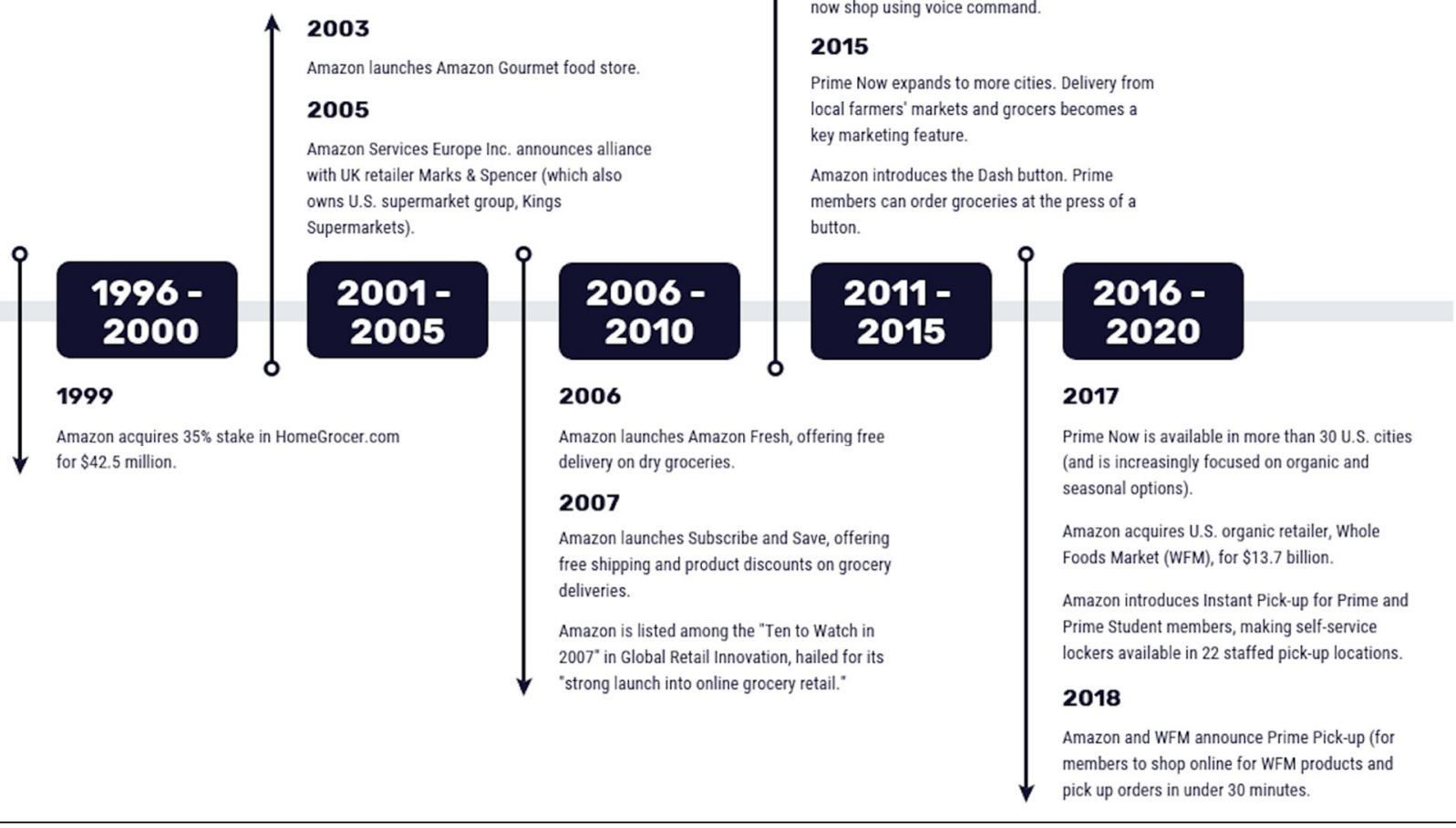


home products, which also owns the U.S. supermarket group, Kings Supermarkets (Amazon, 2005). While not an acquisition, the alliance stipulated that Amazon would host and provide the technology behind the Marks \& Spencer-branded website. In 2006 the launch of Amazon Fresh offered consumers free delivery on dry groceries including Kraft and Kellogg products, and natural and organic brands like Annie's Homegrown (Amazon, n.d.-a; Leighton, 2019). The following year Amazon launched Subscribe \& Save, offering customers free shipping and product discounts on grocery deliveries (Amazon, n.d.-e). In 2007 Amazon's Grocery store was hailed for its "strong launch into online grocery retail" by international food and grocery experts IGD (as cited in Amazon, 2007, para. 4), and it was listed among the "Ten to Watch in 2007" in Global Retail Innovation (Amazon, 2007).

Between 2008 and 2014, Amazon was relatively quiet in the food space, announcing little besides the launch of the Amazon Wine Store in 2012 and the expansion of Amazon Grocery to Canada and Australia. Then, in 2014 it launched Prime Now, a one-hour delivery of items (including fresh produce, prepared meals and baked goods) from local stores in New York City. Throughout 2015 and 2016, Prime Now expanded to other cities where delivery from local farmers' markets and grocers became a key marketing feature.

In 2015, Amazon introduced the Dash Button, an electronic device enabling Prime members to replenish frequently ordered goods with the (literal) press of a button. Food options were gradually added and there are now Dash buttons for Clif Bars, Nature Valley, and hundreds of other brands. By late 2017, Prime Now was available in more than 30 U.S. cities, with an increasing focus on the provision of organic and seasonal options. Amazon announced the launch of Prime Now in Seattle stating, "Prime members will find organic produce and meats from the region's best producers, madefrom-scratch foods, freshly baked organic, nonGMO breads...from New Seasons Market" (Amazon 2017, para. 1). Following the 2014 launch of the Amazon Echo and Alexa (wireless speaker and voice command devices) shoppers could shop using their voice.
In June 2017, Amazon announced the acquisition of WFM, the largest U.S. organic retailer, for US $\$ 13.7$ billion. Jeff Bezos, Amazon’s CEO, announced its strategy for WFM, citing a fourpronged approach that would include lower prices; making Amazon Prime the new customer rewards program; making WFM private label products available through Amazon.com, AmazonFresh, Prime Pantry, and Prime Now; and, making Amazon lockers available in select WFM stores, for local pick-up and item returns.

In August 2017 Amazon introduced Instant Pickup, a free service offering Prime and Prime Student members a "curated selection of daily essentials" (Betters, 2017, para. 2), made available in self-service lockers in 22 staffed pick-up locations on or near a college campus in the U.S. In late 2018, Amazon and WFM announced the introduction of Prime Pick-Up, an option for members in select cities to shop online for WFM products and pick up their order in as little as thirty minutes, without leaving their car. While this section by no means covers all of the moves and innovations Amazon has made in food retail, it does suggest that Amazon's transition into food retail has been methodical and strategic, and therefore its acquisition of WFM was anything but sudden or unprecedented. This case study demonstrates a gradual but consistent series of moves, dating as far back as 1999 and continuing to the present day, to disrupt food retail and replace traditional grocery chains and supermarkets.

\section{Applied Research Methods}

Situating our work in the political economy tradition, we set out to explore Amazon's tactics and strategy in-depth. We relied on an iterative environmental scan. We cast our net wide and surveyed academic and grey literature, as well as media reports, that provide insights into Amazon's business strategy, the tactics deployed over the company's two-and-a-half-decade-long existence, and the reservations that other analysts have voiced regarding Amazon's commercial successes. The resulting synthesis is equally descriptive and analytical, as we attempt the reveal the "big picture" story of Amazon and its surreptitious entry into the food retail space. 


\section{Analysis}

Amazon's expansion from its already dominant position in global e-commerce into fresh food retail, a highly regulated sector with typically slim profit margins, is a product of multiple motivations, enablers and tactics. The key aspect of this development is Amazon's overall business strategy, which was already well-suited to the risky business of online groceries. While food retail is strictly regulated, the e-commerce regulatory environment is lax and caters almost solely to consumer welfare. In concert, strategy and regulation allow Amazon to use groceries as the gateway into a world in which customers can purchase all goods from them, becoming what Bezos considers "Earth's most consumer-centric company" (Amazon, 2018, p. 7).

\section{Amazon's Business Strategy is Conducive to Risky, Low-Profit Online Grocery Business} Jeff Bezos' first letter to shareholders in 1997 laid out his vision for the future of Amazon. Its longterm investment philosophy would center around extending and solidifying Amazon's market leadership position, and the metrics of success would be "customer and revenue growth" and "the degree to which...customers continue to purchase from [Amazon] on a repeat basis" (Bezos, 1997, p. 2). A balance would be struck between growth, longterm profitability, and capital management; critically, Amazon would "choose to prioritize growth," believing that "scale is central to achieving the potential of [its] business model" (Bezos, 1997, p. 8).

Bezos recognized that becoming consumers' one-stop-shop would require investing aggressively and spending billions to expand capacity (Khan, 2016). Bezos was playing the long game. Amazon's prioritization of growth at the expense of shortterm returns also hinged on a second, related strategy: to "sustain losses" while "integrat[ing] across multiple business lines" (Khan, 2016, pp. 746-747). These strategies enable Amazon “...to leverage advantages gained in one sector to boost its business in another" (p. 747). A customer-first approach underpins the strategies of growth-overprofit and integration across business lines. Bringing new value to customers through e-commerce and merchandizing, while solidifying and extending Amazon's brand and customer base were explicit goals for 1998 (Bezos, 1997). This required “... sustained investment in systems and infrastructure to support outstanding customer convenience, selection, and service while we grow" (Bezos, 1997, p. 4).

Additionally, Amazon's place in data and dataservice markets has given it tremendous commercial stature. The systems and infrastructure requiring investment cannot be disentangled from the big data platform that enabled Amazon's development and that now helps keep and grow Amazon's customer base. While retail is Amazon's "core" business, what gives Amazon the freedom to take risks in chancy, regulated, low-profit-margin industries are its nonprimary business offerings that are much more profitable: Amazon Web Services (AWS), Amazon Prime, and Marketplace with Amazon's accompanying ad business.

Following that 1997 letter, Amazon spent two decades taking risks, incurring losses, and investing heavily in systems and infrastructure to develop what it now refers to as its "three pillars" or "life partners." AWS, Amazon's "secure cloud services platform, offering compute power, database storage, content delivery and other functionality to help businesses scale and grow" (Amazon, n.d.-g, para. 1), is now the world's biggest cloud computing business (Dastin, 2017). In 2018, AWS accounted for US $\$ 7.8$ billion in operating income (Condon, 2019). Marketplace, a platform that charges a fee to retailers to sell their wares alongside Amazon products, gives sellers "access to the world's largest e-commerce platform and customer base" (Galloway, 2017, p. 25), allowing Amazon to vastly expand its offerings without the expense of carrying additional inventory. Sellers can pay to have their wares appear as top search results, generating additional advertising revenue for Amazon. Most critical to the push into food retail is Amazon Prime. While "originally designed as an all-you-can-eat free and fast shipping program" (Bezos, 2014, p. 2), Prime has become a "physicaldigital hybrid that members love" (Bezos, 2014, p. 2), offering "free two-day and same-day shipping on eligible orders and other benefits" (Amazon, n.d.-b, para. 1). 
Amazon made massive investments in these three pillars, which now have a staggering degree of architectural flexibility and scalability, making Amazon the "world's most valuable public company" in 2019 (Oreskovic, 2019, para. 1). These pillars enable Amazon to integrate across business lines. Whereas Amazon's acquisition of WFM is what made food systems analysts take note, it is these pillars that have allowed for Amazon's much subtler but pervasive penetration across the agrifood value chain. We next take a closer look at two services that have infiltrated the agri-food sector through a process of stealth: AWS and Amazon Prime.

\section{AWS in the Food System}

AWS provides cloud-based services to large-scale agribusiness, U.S. federal regulators, and retailers. Bayer Crop Science, one of the world's largest agricultural companies (Amazon, n.d.-i, para. 1), relies on AWS Internet of Things (IoT) devices to enable real-time data collection "to get seed data to analysts in just a few minutes instead of a few days" (Amazon, n.d.-i, para. 3). The U.S. Department of Agriculture (USDA) Food and Nutrition Service, which administers nutrition assistance programs, also relies on AWS to host its web application SNAP Retailer Locator, to direct the nearly 47 million nutrition benefits recipients to the nearest authorized store (Amazon, 2014a). The U.S. Food and Drug Administration, whose mandate includes ensuring the safety of the U.S. food supply ("What We Do," 2018), relies on AWS to, among other things, make its "data entry process more efficient and reduce costs" (Amazon, 2014b, para. 1).

At the time of Amazon's acquisition, WFM was relying on Microsoft for software as a service (SaaS) (Novet, 2017, para. 1) in place of applications developed in-house (Microsoft, 2016). AWS and WFM have thus far refused to comment on whether WFM would adopt AWS and move away from Microsoft (Novet, 2017, para. 6).

As more actors rely on the AWS cloud-services architecture, the architectural advantages of large sites set the conditions for a digital economy of scale, wherein large firms become more efficient as they scale up (Hindman, 2018, p. 20). The develop- ment of networking infrastructure, hardware, and software has resulted in cheaper (per computer) data centers, allowing Amazon to "deploy more computing power, and bandwidth per dollar than smaller firms" (Hindman, 2018, pp. 22-23).

The flexibility of AWS's vast computing possibilities is critical to its success. As Hindman (2018) states, "while web-scale data centers are an enormous upfront cost, they can be adapted to do many different tasks" (p. 23). Amazon has gleaned immense benefit from integrating its web-scale technologies and applications (Hindman, 2018), users of which include conglomerates like Kellogg's and Unilever (Amazon, n.d.-c), and local and national governments that now use AWS's GovCloud to meet their growing cloud-computing needs (Amazon, n.d.-d). AWS has positioned itself as an underlying data architecture that works across business lines. The result is what Bezos enthusiastically refers to as a "dreamy business offering," that is "market-size unconstrained," whose opportunity encompasses ". . . global spend on servers, networking, datacenters, infrastructure, software, databases, data warehouses and more" (Bezos, 2014, p. 4). Bezos recognizes the "stickiness" with AWS, stating that as more customers (individuals, businesses, and governments) become comfortable and proficient with AWS tools, it will be only rational that they stay with what they know (Bezos, 2014, p. 4). As Amazon conducts more business across the food system, making governments, regulators, agribusiness, and retailers increasingly reliant on their services, these developments should raise serious questions about the company's control and power and who is (or is not) going to check its power.

\section{Amazon Prime: Supply Chain Innovation}

If AWS is the infrastructure that makes companies and governments increasingly reliant on Amazon, then Prime is the ever-adaptable flywheel that keeps customers coming back. Prime, described in 2015 as a money-pit (Mangalindan, 2015, para. 7), more recently as an innovator in supply-chain management (Leblanc, 2019), and now as the world's most ingenious customer loyalty program (Bruceb Consulting, 2017), emerged out of Amazon's early goal to grow customer loyalty. 
With fast and free shipping, Bezos sought to make Prime so valuable that "you'd be irresponsible not to be a member" (Bezos, 2015, p. 2).

Prime required massive investments and years of profit losses. It launched publicly in 2005 with an annual membership fee of US\$99. Members received guaranteed two-day shipping on hundreds of thousands of products (Amazon, n.d.-b). Bezos admitted these were "bold bets" (Bezos, 2015, p. 1) to develop quick and efficient supply-chain management. First, Amazon outsourced inventory management and insourced logistics (Leblanc, 2019). By outsourcing inventory management to third-party sellers (which account for nearly 82 percent of Amazon's sales) but relying on its own delivery logistics to deliver, Amazon would be able to use its own delivery vehicles and systems to ensure shorter delivery timelines (Leblanc, 2019). Second, Amazon began to rely on "different warehouses for different kinds of products and customer preferences for delivery options" (Leblanc, 2019, para. 6) that range from one-day delivery, free super-saver delivery, and now 1 to 2 hour delivery. Third, Amazon enabled a push/pull strategy, wherein “Amazon's own warehouses are strategically placed, moving closer and closer to main metropolitan areas and city centers," which acts as a "push strategy for the products it stores in its warehouses" (Leblanc, 2019, para. 7). The pull strategy is alternatively employed when Amazon sells products from third-party sellers, who store their own goods but rely on Amazon to pick up and deliver the products (Leblanc, 2019).

The fourth strategy pertains to the location, size, and number of warehouses critical to Amazon's successful supply chain (Leblanc, 2019); Amazon now has "75 fulfillment centers and more than 125,000 full-time employees" in North America alone" (About Amazon Staff, n.d., para. 1), strategically "positioning warehouses in proximity to local urban markets" (Leblanc, 2019, para. 8). The fifth strategy involves automation. In 2012, Amazon acquired Kiva Systems, a "provider of automated and robotic warehouse solutions" (Leblanc, 2019, para. 9). Cutting-edge technology and robotics were introduced into Amazon's fulfillment center (About Amazon Staff, n.d.), where robots "pick and pack without ... human assistance" (Leblanc, 2019, para. 9).

The rate of Amazon's innovations in supplychain management makes it difficult for other companies to compete (Leblanc, 2019). Amazon is "forcing its major competitors to invest more in supply-chain automation, lessen the overall product delivery time, [and] increase the number of warehouses ..." (Leblanc, 2019, para. 20), and it has contributed to shifting customer demand. Bezos wrote in his 2016 letter to shareholders: "no customer ever asked Amazon to create the Prime membership program, but it sure turns out they wanted it ..." (Bezos, 2016, p. 1). As consumers learned that they could expect quicker delivery at no added cost, retailers faced intense pressure to adapt (Leblanc, 2019). Prime helped Amazon grow into the large company it is today, “... and there are certain things that only large companies can do" (Bezos, 2015, p. 1).

\section{Amazon Prime in the Food System}

Amazon's early prioritization of efficient supplychain management and, significantly, its focus on automation and technological innovation both have contributed to an architectural advantage required to offer Prime members increasingly fast delivery. But research on the failure of e-grocers shows that improved supply-chain operations are "not enough to reach a significant market share in the grocery market" (Kämäräinen \& Punakivi, 2010 , p. 292), as "a range of new value-added services is also needed" (p. 292). Herein lies the impetus for the seemingly never-ending assortment of what Amazon Prime refers to as "other benefits" (Amazon, n.d.-b) intended to attract and maintain audiences (Hindman, 2018, p. 23), or in this case customers.

With more than 100 million Prime members, Amazon has been boosting the benefits linked to its grocery services, "enticing consumers to spend more via a growing number of discounts linked to Prime membership" (Brick Meets Click, 2018, p. 3). This makes sense, given that members, on average, spend twice as much per year compared to non-members (Floship, 2017, para. 15). Prime is the gateway through which to attract more members and encourage existing members to spend more. "Convenience [is] the true source of loyalty," 
and no business offering does it better than Prime (Baille, 2018, para. 16).

Prime and Amazon's Food Business: Integration Over Time

Amazon has been integrating Prime into multiple aspects of its food business since Prime's launch in 2005. From offering customers free shipping on dry grocery products in 2006, to one-hour delivery service from local farmers' markets and grocers in 2015 via Prime Now, Prime's perks have evolved. But the power of Prime has also grown to such an extent that it actually drives Amazon to integrate across any number of business lines. In food retail, Prime can no longer be separated from in-store logistics, check-out, and delivery. The clearest example of this process of integration is Amazon's acquisition of WFM.

In a press release following the closing of the acquisition on August 28, 2017, Amazon and WFM announced their intent to make "high-quality, natural and organic food available for everyone" (WFM, 2017, para. 1). On the Monday following the acquisition, WFM's prices of typically high-cost groceries such as organic brown eggs, responsibly farmed salmon, and avocados were slashed, in what the WFM press release called a "downpayment" on their joint vision to make organic affordable without jeopardizing the high standards expected by WFM shoppers (WFM, 2017). Central to the acquisition was, however, Prime. Press releases from both Amazon and WFM publicized their plans to integrate Prime into the WFM pointof-sale system, promising special savings and instore benefits for Prime members and, in time, inventions surrounding merchandizing and logistics that would ultimately result in lower prices for WFM customers (WFM, 2017).

A second round of price cuts came a few months later to coincide with the launch of Prime member exclusive promotions (which broke the WFM all-time record for turkeys sold during the Thanksgiving season) (WFM, 2018b). Free twohour delivery on orders over US $\$ 35$ for Prime members was introduced in select cities (Amazon, n.d.-f) and benefits of the Amazon Prime Rewards Visa Card were expanded to give Prime members five percent back when shopping at WFM (WFM, 2018a). WFM private-label products were quickly integrated into Amazon's online platform so that customers could order online and have their WFM groceries delivered (for free with Prime). Further, lockers were integrated into the physical WFM stores to allow Amazon customers to pick up and/or return Amazon packages (not only grocery orders, but any Amazon product offering) (Gebel, 2019). Amazon devices (Echo, Dash buttons, and Alexa Home Systems) were integrated into the physical WFM stores for purchase and Amazon began "the technical work needed to recognize Prime members at the point of sale" (Hu, 2018, para. 5).

Today, all of Amazon's promises have been implemented. Cashierless grocery stores, "Amazon Go," that require Prime members to be recognized at point of sale so that they may take items off store shelves and be automatically charged for the items upon exiting, have rolled out in nine locations. At this point, Amazon Go locations are replacements for convenience stores, and while Amazon is testing cashierless technology in larger spaces with layouts similar to grocery stores, Amazon has not yet commented on the potential roll-out of these systems to WFM locations (Detrick, 2018).

Acquiring WFM gave Amazon 460 physical, brick-and-mortar stores in urban centers, close to a more affluent consumer base with an existing relationship to WFM products (Galloway, 2017). Amazon's greatest expense is and has always been shipping, and despite its success in obtaining greater market share in groceries, it has struggled to overcome multiple challenges (like other e-commerce retailers), including consumers' lingering preference to shop offline for their groceries (particularly meat and fresh produce) (Galloway, 2017). What this adds up to is "stickiness" - using online and offline economies of scale to keep customers coming back and maintaining Prime's ability to stay flexible and adopt innovations and new business ventures to reinforce customer loyalty.

\section{Discussion: Implications for the Food System and Beyond}

If Amazon's trajectory to grocery domination persists as anticipated, the consequences of this con- 
centration will arguably be more severe than in most retail sectors, with implications that reach beyond food retail. As an internet company, Amazon is able to leverage its existing technological dominance and big data platform to innovate, implement, adapt, and grow at a pace that grocery stores, supermarkets, and other traditional food retailers have never had the capacity to do (nor were ever in the business of doing). Amazon spent years investing in high-cost, high-risk logistics systems and an extensive e-retail platform (Oja Jay, 2018). Now positioned as one of the world's largest data managers (Mooney, 2018), Amazon can "amass and analyse incredible quantities of data to extract commercially-relevant information" like never before (Oja Jay, 2018, p. 3). Generally speaking, those with massive platform capabilities are disruptive because of their ability to "[shift] the commercial advantage to the companies that have the most data and are most able to manipulate it" (Oja Jay, 2018, p. 3).

In July 2018, Microsoft announced a 5-year strategic partnership with Walmart to "accelerate Walmart's digital transformation in retail, empower its associates worldwide and make shopping faster and easier for millions of customers around the world" (Microsoft, 2018, para 1). In the vague media release, Microsoft indicated that the pair would embark on a "broad set of cloud innovation projects that leverage Machine Learning, Artificial Intelligence, and data platform solutions for a wide range of external customer-facing services and internal business applications" ("Walmart Establishes," 2018, para. 4). Around the same time, Reuters and others announced that Microsoft, like Amazon, was working on the development of cashierless technologies (Dastin \& Nellis, 2018). In 2019, Walmart proudly announced a series of innovations being piloted or integrated into stores, from automated shelf scanners that "identify where in-stock levels are low, prices are wrong or labels are missing" (Walmart, 2019, para. 10), to the 'alphabot,' which uses autonomous mobile carts to deliver items from storage to store associates who prepare and deliver orders to customer vehicles (Walmart, 2019, para. 9).

In January 2019, grocery giant Kroger announced a partnership with Microsoft to "redefine the customer experience and introduce digital solutions for the retail industry" (Kroger, 2019, para. 1). They started by piloting two stores with an integrated smart technology system "powered by Microsoft Azure and connected by IoT sensors" to market new a Retail-as-a-Service (RaaS) product to the industry (Kroger, 2019). Like AWS, RaaS is a commercial product marketed to the rest of the grocery retail sector that "offers a suite of capabilities to support [key performance indicators] and merchandising plans, collect consumer insights, enhance employee productivity, improve out-of-stocks, better the customer experience, and allow for hyper-personalization using proprietary technology" (Kroger, 2019, para. 7).

Kroger and Walmart are just two examples of traditionally dominant retailers jumping feet first into the grocery data competition. Other partnerships have been emerging, including Microsoft's recent pairing with Albertsons (Liptak, 2019), which is the second largest grocery chain in the U.S., (having acquired Safeway in 2014; see iPESFood, 2016), and Google's partnership with French grocery chain Carrefour for online food delivery (Shoot, 2018). Costco, too, has joined the ranks offering same-day delivery after establishing a partnership with online grocery delivery service Instacart (Bloomberg, 2019).

The consequences of this rapid race to datafication remain to be seen, but it seems likely that these changes will facilitate even greater market concentration in food retail. Food retail markets are highly concentrated regionally due in large part to food products being "purchased by individuals in the direct vicinity of their home, meaning that the concentration of retailers in a given region is what matters in terms of shaping food systems and food choices" (iPES-Food, 2016, pp. 43-44). Purchasing regionally traditionally has required that grocers have a brick-and-mortar store everywhere, which has been difficult for even the biggest food retailers and has kept them "small" (Oja Jay, 2018, p. 15). Amazon's use of its big data platform and the lax enforcement (and perhaps insufficient nature) of antitrust regulation, however, is paving the way for a restructuring in the food system that will create players bigger than the food retail space has ever seen before. Big data does, after all, 
demand concentration; as ETC Group notes, "...no company at any point in the [food] chain can risk allowing others to gain control of more information" (Mooney, 2018, p. 10). This restructuring is playing out with dominant firms expanding in multiple directions (Howard, 2016). Vertical integration, or the act of "firms buying upstream suppliers or downstream retailers," both nationally and globally in order to become "more directly involved in other stages of the food system" (Howard, 2016, p. 24), is becoming increasingly common (Howard, 2016).

While Amazon prepares to control the food retail ecosystem, Walmart is acquiring logistics and fulfilment companies across the globe, such as Parcel, a "technology based, same-day and lastmile" (Walmart Staff, 2017, para. 1) food delivery company in New York City, and Cornershop, a food delivery service in Latin America, to help escalate its online grocery business in Mexico and Chile (Solomon, 2018). Costco is vertically integrating into meat production (with plans to launch in-house poultry production, see Devenyns, 2018) in a move to "better manage supply and costs" (Gerlock, 2018, para. 5). This move comes at a time when the highly concentrated poultryproduction sector is "trending away from raising chickens to be sold whole" (Gerlock, 2018, para. 5); Costco sells approximately 60 million rotisserie chickens per year.

Traditionally dominant supermarkets like Walmart, Costco, and Kroger are recognizing that survival hinges on bridging the offline/online divide. Amazon is neither the inventor nor the agitator of concentration in the food value chain, but it appears to be laying a new framework for success, ploughing through traditional food retail barriers to enact standalone supply chains that afford them a level of control unprecedented in food retail. Likewise, the world's largest tech companies have recognized that the fight for control of the grocery market is one well worth jumping into. But, while the largest retailers have the money and scale to invest in costly digital acquisitions and partnerships, food retailers that are local or regional and/or independently owned, and that operate at small and medium scales, will be left to navigate a different landscape entirely, and space for new entrants into this sector will shrink even further.

Faced with the 'adapt-or-die' ultimatum of offering both online and offline services, smaller players in food retail that lack the logistics and fulfillment systems and online platforms may be increasingly forced to "choose" Amazon. Food processors, too, are facing increasing pressures felt across the manufacturing sector to sell through Amazon if they want to succeed or even survive (Del Rey, 2019). Whether it is Instacart (online grocery delivery platform) or Eataly (a provider of Italian food and beverages) ("Retail Case Studies," n.d.) using AWS for its online service offerings, or one of the many food processors and grocery stores using Amazon's Marketplace, competitors are now Amazon's customers; those customers are increasingly at the whim of Amazon as the setter of terms.

The more "customers" Amazon has, the more data-grabbing it can execute and monetize. Alistair Fraser defines data-grabbing as "... firms (and government agencies) ... gathering as much data as possible from customers (and from those with whom customers interact online) ... to inform innovations and direct strategic investment" (Fraser, 2019, p. 895). As Amazon grabs more data "add[ing] value (by aggregating or packaging)," algorithms use those data to "target consumers with ads and services, thereby shaping subjectivities" and increasing their competitive advantage (Fraser, 2019, p. 895). As Alexa's capabilities expand, for example, it will be increasingly able to proactively recommend specific grocery items. Additionally, because of the edge Amazon has over traditional food retailers in its ability to monetize data, it has a permanent advantage to "use a price point unsustainable or flat out unachievable for other retailers" (Clinton, 2018, para. 21). In making competing food retailers into customers, Amazon gains the ability not only to set terms around what products are made visible and available, and the cost of those products, but also what should be surveilled of consumers, how market data can and should be used, who controls it, and what enforcement mechanisms are enacted (or not) to make Amazon the default grocery provider.

Retailers that avoid Amazon, for whatever 
reason (cost, scale, philosophy), may not be much better off. Patrick Clinton sums it up well; "sure, a regional, family-owned grocery chain can use loyalty cards to collect data about what its customers buy and what price points they're sensitive to ... but Amazon can use what it learns in one realm to make predictions about entirely other realms" (2018, para. 21). As ETC Group notes, people “"use' food every day — and buy it every other day" (Oja Jay, 2018, p. 15). Smaller food retailers in the past have benefited from their ability to be consistent, physical providers that consumers preferred. That advantage is slipping away, as "food doesn't even need to make companies like Amazon money if customers fill their carts with other 'stuff" (Oja Jay, 2018, p. 15).

How can small, independent retailers compete in a new environment, where the company consumers rely on for a basic necessity like food are actually not even truly "in the business" (Clinton, 2018, para. 20) of food? Tech companies are playing an entirely different retail game, and traditional grocery giants are scrambling to follow suit. The smaller players, however, will struggle to make supply and price decisions based on limited information, while Amazon and others mine massive amounts of data for a detailed understanding of consumer food habits and preferences. As Hindman (2018) reminds us, sites like Amazon render digital economies of scale inaccessible to small retailers, where "only the biggest sites can personalize ads and content efficiently" (p. 163).

\section{Beyond Retail}

Whereas implications of these developments are the most obvious in retail, they are also far reaching elsewhere in the food system. Retail concentration has significant impact along the entire value chain and has been shown to present significant challenges to producers and processors (Hendrickson, Howard, \& Constance, 2017; Lang, 2004), as well as other distribution actors (Friedmann, 2007). If Amazon is successful in becoming one of two or three global food retailers, as is predicted to occur in the next ten years, it may likely have the power to negotiate with the other retail giants to "determine what food will be harvested from the fields and oceans and what will be brewed and baked by robots" (Mooney, 2018, p. 35).

Prominent groups have in recent years called for a move away from the concentrated, industrial food system (FAO, iPES Food) and diversification of food systems around the globe. This diversification refers as much to size and scale as it does to biodiversity in production (iPES-Food, 2016, p. 69). In the industrialized world, there is a movement afoot to rebuild community food systems and in recent years there has been growth in local food businesses, community gardens and kitchens, local food hubs, farmers' markets, food-related social enterprises, and other types of community food initiatives (Winnie, 2010). But this growth is leveling off. For instance, between 2007 and 2012, direct-to-consumer farm sales in the U.S. grew by eight percent to reach US $\$ 1.3$ billion (USDA, 2014, p. 1). Three years later, the sales more than doubled to surpass US $\$ 3$ billion (USDA, 2016, p. 2). But the 2017 U.S. agricultural census shows a drop in direct-to-consumer farm sales for the first time in years, down to US $\$ 2.8$ billion (White \& King, 2019, para. 4). Recent analysis of this data by O'Hara and Benson (2019) points to online sales as likely one of key factors in this decline. Whereas online platforms have opened up opportunities for direct-to-consumer sales for small producers and processors, many of which are trying to sell locally (Carolan, 2017), the trends described above indicate that such platforms have yielded more opportunities for the large players. As O'Hara and Benson point out, even direct-to-consumer online sales by small enterprises "conceivably can occur across any distance" (2019, p.33), which would suggest that in addition to revealing the decline in sales, the census numbers may also be obscuring other developments that could undermine community food systems.

Agri-food conglomerates are already adding data and related technologies to their portfolios, allowing for even greater integration across sectors. This integration comes with troubling consequences such as consolidation of power, tougher competition for small players, and increased barriers to entry for new enterprises (Bronson \& Knezevic, 2016; Fraser, 2019; Mooney, 2018). Amazon is moving from the other directionrather than being an agri-food company entering 
data markets, it is a data company entering the food sector. The implications, however, are similar, and the above noted relationship with Bayer Crop Science suggests that rather than these being discreet market dynamics in the food-data mix, they are a sign of cross-sectoral convergence.

\section{Conclusion}

Amazon challenges the notion that contemporary commerce is preoccupied with short-term profit. We have demonstrated that Amazon's business strategy, combined with an inadequate regulatory regime, enabled it to enter into the risky and complex business of food retail through stealth. Amazon's willingness to forego short-term profit in the name of long-term growth led to the development of flexible, scalable, and profitable business pillars (Pappageorge, 2017). These pillars, which required aggressive and costly investments in the early years, became the tools that contributed to Amazon's integration across any number of business lines. Amazon acquires companies up and down the supply chain in any and every sector, in an effort to streamline services, under the guise of creating a frictionless experience for customers.

In a regulatory environment that is always behind the big-tech developments, Amazon thrives. Active or would-be competitors are eliminated by acquisition; those that become customers are mined for data and business knowledge, leading to cloning of products or services (Wu, 2018, p. 125) and then Amazon's marginalization of those same companies by, for example, privileging their own products online. Individuals are not exempt; their data too, is mined and monetized. In the context of modern-day tech trusts, data implications for privacy and data control are critical. Yet, as iPESFood notes, these implications are a blind spot in antitrust regulation $(2017$, p. 80$)$. Viewed in the context of food retail, then, is the realization that Amazon's acquisition of WFM in 2017 was not a new play for the tech company, nor were its previous forays (Amazon Fresh, etc.) or subsequent moves (Amazon Go, etc.) out of character. Instead, food retail is merely collateral damage in what is a stealthy, larger quest to become "Earth's Biggest Store." We see this as particularly dangerous for food retail and food systems in general.
In light of the new business models employed by big-tech and a regulatory system that is perpetually playing catch-up, we add our voices to the movement of scholars and governments calling for a reassessment of antitrust laws. This call for an end to self-regulation by big-tech companies is gaining momentum, particularly with U.S. regulators seeking to investigate antitrust activities and the implications of data collection and analysis on privacy and democratic processes more broadly. The case of Amazon is one of many contributing to this movement (United States Senator Elizabeth Warren has called for the uncoupling of anticompetitive mergers like Amazon's acquisition of Whole Foods). The particularly dangerous ramifications of unchecked, concentrated power in food retail for all links in the food chain necessitate that those working in the development of food systems policy add their voices and expertise to this movement.

Beyond regulation, the advancement of food policy that guides and drives local food systems is arguably necessary now more than ever. Ensuring food systems are participatory, resilient, and serve to improve the health and well-being of people, the environment, and the economy can be advanced in part by policies that promote and incentivize local food infrastructure and take a coordinated, peoplecentric approach to food policy and governance. The inclusion of a funding line for a Canadian national food policy in the 2019 federal budget is one example of a promising step forward in the establishment of a coordinated food systems approach, but it will require continued advocacy and political will in order to come to fruition as an operational food policy.

This case study also has implications for the future of food systems research. Our observations may not surprise scholars in critical data studies and communication studies where Amazon and its impact on other sectors have been watched with interest for years. But food systems scholars have not given much attention to Amazon and other tech giants. Whereas some scholarship is emerging on the impact of data technologies and the associated power in relation to agriculture (Bronson \& Knezevic, 2016; Carolan, 2017; Fraser, 2019), we now require similar attention paid to the retail end 
of the food chain where implications are no less critical. Additionally, while communication, digital media studies, and other domains traditionally focusing on the impacts of big-tech and data on retail markets have often grouped food retail together with any number of other businesses (from personal-care to books and furniture), future scholarship should take into account the unique complexities and ramifications of big-tech and data on food retail and food systems more broadly. We stress the need for an integrated, interdisciplinary, system-wide approach that includes communication, media, and critical data studies with food retail and food systems domains; our ability to understand, prevent, and respond to potentially dangerous trends and shifts in tech and food retail depends on all of this expertise being at the table.

This same call to attention applies to food systems practitioners. Community organizations, food activists, and regional officials (from public health to planning departments) invested in rebuilding community food systems are typically not well-versed in the trends that characterize the bigtech sector. Given that software-designers are similarly not versed in food systems, the gap between big-tech and community food systems goals is likely to widen. This can only be remedied by deliberate efforts to engage tech developers into conversations about the future of tech in food systems.

Ultimately, the world may be able to afford, or at least adapt to, a reality in which Amazon dominates the book industry. But eaters, producers, food processors, retailers, and community food systems cannot afford domination by the world's biggest tech companies. In the words of ETC Group, "it is not what happens to Amazon or Walmart that matters - it's what happens to food security" (Oja Jay, 2018, p. 15).

\section{Acknowledgments}

We are grateful to Dr. Tracey P. Lauriault (Carleton University) and Dr. Dwayne Winseck (Carleton University) for their insight and feedback on early iterations of this paper. We also thank graduate student Jane Clause (Carleton University) for research assistance and editing over the course of this project.

\section{References}

About Amazon Staff. (n.d.). Amazon's fulfillment network. Amazon. Retrieved from

https://www.aboutamazon.com/working-at-amazon/amazons-fulfillment-network

Amazon. (n.d.-a). About AmazonFresh. Retrieved from

https://www.amazon.com/gp/help/customer/display.html?nodeId $=202052140$

Amazon. (n.d.-b). About Amazon Prime. Retrieved January 20, 2020, from https://www.amazon.ca/gp/help/customer/display.html?nodeId=201025460

Amazon. (n.d.-c). AWS customer success. Retrieved from https://aws.amazon.com/solutions/case-studies/

Amazon. (n.d.-d). AWS in the public sector. Retrieved from https://aws.amazon.com/government-education/

Amazon. (n.d.-e). Subscribe \& Save. Retrieved from https: / $/$ www.amazon.ca $/ \mathrm{b}$ ?ie=UTF8\&node $=17051457011$

Amazon. (n.d.-f). Order with prime free same-day delivery. Retrieved from https://www.amazon.com/gp/help/customer/display.html?nodeId=202052960

Amazon. (n.d.-g). Powering companies from Netflix to NASA. Retrieved January 20, 2020, from https://www.amazon.jobs/en/business categories/amazon-web-services

Amazon. (n.d.-h). Retail case studies. Retrieved from https://aws.amazon.com/retail/case-studies/

Amazon. (n.d.-i). Bayer Crop Science drives innovation in precision agriculture using AWS IoT. Retrieved from https://aws.amazon.com/solutions/case-studies/bayer-cropscience/

Amazon. (1999, May 18). Amazon.com announces minority investment in homegrocer.com [Press release]. Retrieved from https://press.aboutamazon.com/news-releases/news-release-details/amazoncom-announces-minorityinvestment-homegrocercom

Amazon. (2003, November 6). Amazon.com serves up new gourmet food store with thousands of regional specialties and hard-to-find treats [Press release]. Retrieved from https://press.aboutamazon.com/news-releases/news-releasedetails/amazoncom-serves-new-gourmet-food-store-thousands-regional 
Amazon. (2005, April 19). Amazon services Europe and leading United Kingdom retailer Marks \& Spencer form ecommerce alliance [Press release]. Retrieved from $\underline{h t t p s: / / p r e s s . a b o u t a m a z o n . c o m / n e w s-r e l e a s e s / n e w s-r e l e a s e-~}$ details/amazon-services-europe-and-leading-united-kingdom-retailer-marks

Amazon. (2007, May 15). Amazon.com's grocery store launches new subscribe \& save feature allowing automatic fulfillment of most popular items [Press release]. Retrieved from the Business Wire website: https://www.businesswire.com/news/home/20070515005813/en/Amazon.coms-Grocery-Store-Launches-NewSubscribe-Save

Amazon. (2014a). USDA Food and Nutrition Service case study. Retrieved from https://aws.amazon.com/solutions/case-studies/usda-fns/

Amazon. (2014b). AWS case study: U.S. food and drug administration (FDA). Retrieved from https://aws.amazon.com/solutions/case-studies/us-food-and-drug-administration/

Amazon. (2017, January 31). Prime now introduces delivery from new seasons market to Seattle; increases service coverage from Bartell Drugs and All the Best Pet Care [Press release]. Retrieved from https://press.aboutamazon.com/news-releases/news-release-details/prime-now-introduces-delivery-new-seasonsmarket-seattle

Amazon. (2018). Amazon 2017 annual report. Retrieved from https://ir.aboutamazon.com/annual-reports-proxies-and-shareholder-letters/default.aspx

Aziza, B. (2017, June 23). Amazon buys Whole Foods. Now what? The story behind the story. Forbes. Retrieved from https://www.forbes.com/sites/ciocentral/2017/06/23/amazon-buys-whole-foods-now-what-the-story-behindthe-story/\#7471bbe4e898

Baille, S. (2018, August 31). One year later - Whole Foods changes reveal Amazon true retail strategy [Blog post]. Salvador Baille. Retrieved from https://salvadorbaille.com/2018/08/31/one-year-later-whole-foods-changes-reveal-amazon-true-retail-strategy/

Barr, A. (2013). Amazon plans big expansion of online grocery business - sources. Reuters. Retrieved from https://mobile.reuters.com/article/amp/idINDEE9530F720130604

Betters, E. (2017, August 15). What is Amazon instant pickup, who can use it, and how does it work? Pocket-lint. Retrieved from https://www.pocket-lint.com/apps/news/amazon/141909-what-is-amazon-instant-pickup-whocan-use-it-and-how-does-it-work

Bezos, J. (1997). Letter to shareholders. Amazon. Retrieved from https://ir.aboutamazon.com/annual-reports-proxies-and-shareholder-letters/default.aspx

Bezos, J. (2014). Letter to shareholders. Amazon. Retrieved from https://medium.com/@,hooda/every-jeff-bezos-letter-to-shareholders-since-1997-b3cb57914cab

Bezos, J. (2015). Letter to shareholders. Amazon. Retrieved from https://medium.com/@hooda/every-jeff-bezos-letter-to-shareholders-since-1997-b3cb57914cab

Bezos, J. (2016). Letter to shareholders. Amazon. Retrieved from https://medium.com/@hooda/every-jeff-bezos-letter-to-shareholders-since-1997-b3cb57914cab

Bloomberg. (2019, February 26). Costco is loved by shoppers—even more than Amazon. Fortune. Retrieved from https:// fortune.com/2019/02/26/costco-amazon-best-stores/

Brick Meets Click. (2018, July). How the online grocery market is shifting. Brick Meets Click. Retrieved from https://www.brickmeetsclick.com/stuff/contentmgr/files/0/50078daf4a2e6b5c1c58cbd58d63b69b/pdf/bmc onli ne groc shopper report final v2.pdf

Bronson K., \& Knezevic, I. (2016). Food studies scholars can no longer ignore the rise of big data. Canadian Food Studies / La Revue canadienne des études sur l'alimentation, 3(1), 9-19. https://doi.org/10.15353/cfs-rcea.v3i1.138

Bruceb Consulting. (2017, July 10). Amazon's secret weapon is of prime importance [Blog post]. Retrieved from https://www.brucebnews.com/2017/07/amazons-secret-weapon-is-of-prime-importance/

Carolan, M. (2017). Agro-digital governance and life itself: Food politics at the intersection of code and affect. Sociologia Ruralis, 57(S1), 816-835. https://doi.org/10.1111/soru.12153

Clinton, P. (2018, April 24). What's behind Amazon's food obsession? The Counter. Retrieved from https://thecounter.org/amazon-a-whole-foods-growth-profit/ 
Condon, S. (2019, January 31). In 2018, AWS delivered most of Amazon's operating income. ZDNet. Retrieved from https://www.zdnet.com/article/in-2018-aws-delivered-most-of-amazons-operating-income/

Culpepper, P. D., \& Thelen, K. (2019). Are we all Amazon primed? Consumers and the politics of platform power. Comparative Political Studies, 53(2), 288-318. https://doi.org/10.1177/0010414019852687

Danziger, P. N. (2018, January 18). Online grocery sales to reach $\$ 100$ billion in 2025; Amazon is current and future leader. Forbes. Retrieved from https://www.forbes.com/sites/pamdanziger/2018/01/18/online-grocery-sales-toreach-100-billion-in-2025-amazon-set-to-be-market-share-leader/

Dastin, J. (2017). Disruption in Amazon's cloud service ripples through Internet. Livemint. Retrieved from https://www.livemint.com/Industry/VeuXuBvW29B8x9OOkhfkML/Disruption-in-Amazons-cloud-serviceripples-through-Interne.html

Dastin, J., \& Nellis, S. (2018, June 14). Exclusive: Microsoft takes aim at Amazon with push for checkout-free retail. Reuters. Retrieved from https://www.reuters.com/article/us-microsoft-store-exclusive/exclusive-microsoft-takesaim-at-amazon-with-push-for-checkout-free-retail-idUSKBN1JA0D5

de Koster, M. B. M. (2002). Distribution structures for food home shopping. International Journal of Physical Distribution \& Logistics Management, 32(5), 362-380. https://doi.org/10.1108/09600030210434152

de Koster, M. B. M., \& Neuteboom, A. J. (2001). The logistics of supermarket chains: A comparison of seven chains in the Netherlands. Doetinchem: Elsevier.

Del Rey, J. (2019, August 27). Episode 7: Is Amazon too big? We ask its sellers. Land of the Giants [Podcast]. New York: Vox Media. Retrieved from https://www.vox.com/land-of-the-giants-podcast

Detrick, H. (2018, December 3). A cashierless Whole Foods near you? Amazon's checkout-free tech is reportedly bound for bigger stores. Fortune. Retrieved from https://fortune.com/2018/12/03/amazon-cashierless-stores-whole-foods-big/

Devenyns, J. (2018, September 24). Costco's in-house poultry production signals a new supply chain approach. Grocery Dive. Retrieved from https://www.grocerydive.com/news/costcos-in-house-poultry-production-signals-a-newsupply-chain-approach $/ 533649 /$

Economy, P. (2019, August 6). Jeff Bezos revealed the secret of Amazon's stunning success in just 3 words. Inc. Retrieved from https://www.inc.com/peter-economy/jeff-bezos-revealed-secret-of-amazons-stunning-success-injust-3-words.html

Floship. (2017, May 9). How Amazon floats all that prime free shipping [Blog post]. Floship. Retrieved from https://www.floship.com/how-amazon-floats-free-shipping/

Fraser, A. (2019). Land grab/data grab: Precision agriculture and its new horizons. The Journal of Peasant Studies, 46(5), 893-912. https://doi.org/10.1080/03066150.2017.1415887

Friedmann, H. (2007). Scaling up: Bringing public institutions and food service corporations into the project for a local, sustainable food system in Ontario. Agriculture and Human V alues 24(3), 389-398. https://doi.org/10.1007/s10460-006-9040-2

Galloway, S. (2017). The four: The hidden DNA of Amazon, Apple, Facebook, and Google. New York, NY: Portfolio/Penguin.

Gebel, M. (2019, May 30). 'What is Amazon locker?': Everything you need to know about Amazon's convenient delivery pick-up system. Business Insider. Retrieved from https://www.businessinsider.com/what-is-amazon-locker

Gerlock, G. (2018, October 22). Costco builds Nebraska supply chain for its $\$ 5$ rotisserie chickens. NPR. Retrieved from https://www.npr.org/2018/10/22/659561091/costco-builds-nebraska-supply-chain-for-its-5-rotisserie-chickens

Hendrickson, M. K., Howard, P. H., and Constance, D. H. (2017). Power, food and agriculture: Implications for farmers, consumers and communities. EconStor Preprints 171171, ZBW - Leibniz Information Centre for Economics. Retrieved from https://ideas.repec.org/p/zbw/esprep/171171.html

Hindman, M. (2018). The internet trap: How the digital economy builds monopolies and undermines democracy. Princeton, New Jersey: Princeton University Press.

Howard, P. H. (2014). Too big to ale? Globalization and consolidation in the beer industry. In M. W. Patterson \& N. Hoalst Pullen (Eds.), The geography of beer: Regions, environment, and society (pp. 155-165). Netherlands: Springer. https://doi.org/10.1007/978-94-007-7787-3 14 
Howard, P. H. (2015). Intellectual property and consolidation in the seed industry. Crop Science, 55(6), 2489-2495. https://doi.org/10.2135/cropsci2014.09.0669

Howard, P. H. (2016). AFHVS 2016 presidential address: Decoding diversity in the food system: Wheat and bread in North America. Agriculture and Human Values, 33(4), 953-960. https:/ /doi.org/10.1007/s10460-016-9727-y

Howard, P. H. (2018). Increasing corporate control: From supermarkets to seeds. In J. Konefal \& M. Hatanaka (Eds.), Twenty lessons in the sociology of food and agriculture (pp. 116-131). New York: Oxford University Press.

Howard, P. H. (2019). Corporate concentration in global meat processing: The role of feed and finance subsidies. In B. Winders \& E. Ransom (Eds.), Global meat: Social and environmental consequences of the expanding meat industry (pp. 31-53). Cambridge, MA: MIT Press.

$\mathrm{Hu}, \mathrm{K}$. (2018, June 11). Amazon to offer Whole Foods discounts to prime members in 23 states. HuffPost. Retrieved from https://www.huffpost.com/entry/amazon-to-offer-whole-foods-discounts-to-prime-members-in-23states_n_5b1e947be4b09d7a3d756451

iPES-Food. (2016). From uniformity to diversity: A paradigm shift from industrial agriculture to diversified agroecological systems. Retrieved from http://www.agroecologynow.com/wp-content/uploads/2016/06/UniformityToDiversity FullReport.pdf

iPES-Food. (2017). Too big to feed: Exploring the impacts of mega-mergers, consolidation and concentration of power in the agri-food sector. Retrieved from http://www.ipes-food.org/ img/upload/files/Concentration FullReport.pdf

Jones, C. B. (2018, March 15). Cracking the toughest nut in ecommerce: Grocery retail. Medium. https://medium.com/@,cberta/cracking-the-toughest-nut-in-ecommerce-grocery-retail-6cdb3f663d6a

Kämäräinen, V., \& Punakivi, M. (2010). Developing cost-effective operations for the e-grocery supply chain. International Journal of Logistics Research and Applications, 5(3), 285-298. https://doi.org/10.1080/1367556021000026727

Khan, L. M. (2016). Amazon's antitrust paradox. Yale Law Journal, 126(3), 712-802. https://digitalcommons.law.yale.edu/ylj/vol126/iss3/3

Kneen, B. (1993). From land to mouth: Understanding the food system. (2nd Ed.). Toronto: NC Press Ltd.

Kroger. (2019, January 7). Kroger and Microsoft partner to redefine the customer experience and introduce digital solutions for the retail industry [Press release]. Retrieved from http://ir.kroger.com/file/Index? KeyFile $=396285733$

Lang, T. (2003). Food industrialisation and food power: Implications for food governance. Development Policy Review, 21(5-6), 555-568. https://doi.org/10.1111/j.1467-8659.2003.00223.x

Lang, T. \& Heasman, M. (2003). Food wars: The global battle for mouths, minds and markets. London: Earthscan. https://doi.org/10.4324/9781849776011

Leblanc, R. (2019, June 25). How Amazon is changing supply chain management. The Balance Small Business. Retrieved from https://www.thebalancesmb.com/how-amazon-is-changing-supply-chain-management-4155324

Lee, C. -S. (2001). An analytical framework for evaluating e-commerce business models and strategies. Internet Research, 11(4), 349-359. https://doi.org/10.1108/10662240110402803

Leighton, M. (2019, June 27). I used AmazonFresh to order groceries to my door next-day- here's how the service works. Business Insider. Retrieved from https://www.businessinsider.com/amazon-fresh-review

Liptak, A. (2019, February 23). Microsoft is teaming up with America's second-largest grocery chain to fend off Amazon. The Verge. Retrieved from https://www.theverge.com/2019/2/23/18237792/microsoft-albertsons-azure365-grocery-gas-shopping-amazon-frictionless-experience

Mangalindan, J. P. (2015, February 3). Inside Amazon prime. Fortune. Retrieved from https://fortune.com/2015/02/03/inside-amazon-prime/

McChesney, R. W. (2013). Digital disconnect: How capitalism is turning the internet against democracy. New York: New Press. Microsoft. (2016). Whole Foods takes natural next step to protect applications in the cloud. Microsoft News Center. Retrieved from https://customers.microsoft.com/fr-fr/story/whole-foods-takes-natural-next-step-to-protectapplications-in-the-cloud 
Microsoft. (2018, July 16). Walmart establishes strategic partnership with Microsoft to further accelerate digital innovation in retail [Press release]. Microsoft News Center. Retrieved from https://news.microsoft.com/2018/07/16/walmart-establishes-strategic-partnership-with-microsoft-to-furtheraccelerate-digital-innovation-in-retail/

Mooney, P. (2018, October 15). Blocking the chain: Industrial food chain concentration, big data platforms and food sovereignty solutions. Retrieved from ETC Group website https://www.etcgroup.org/content/blocking-chain

Morganosky, M. A. \& Cude, B. J. (2002). Consumer demand for online food retailing: Is it really a supply side issue? International Journal of Retail \& Distribution Management, 30(10), 451-458. https://doi.org/10.1108/09590550210445326

Mosco, V. (2009). The political economy of communication (2nd ed.). London: SAGE Publications.

Mosco, V. (2017). Power, politics and political economy. In Becoming digital (society now), (pp. 57-96). UK: Emerald Publishing Limited. https://doi.org/10.1108/978-1-78743-295-620181003

Nielsen. (2018a, July 25). Why e-commerce shouldn't be your only focus. Nielsen. Retrieved from https://www.nielsen.com/us/en/insights/article/2018/why-e-commerce-shouldnt-be-your-only-focus/

Nielsen. (2018b, November 19). Global online grocery purchasing is up 15\% in last two years, leading to an estimated US\$70B in additional sales in online FMCG. Retrieved from https://www.nielsen.com/ca/en/pressreleases/2018/global-online-grocery-purchasing-is-up-15-percent-in-last-two-years/

Novet, J. (2017, June 16). Amazon's massive acquisition brings with it a Microsoft cloud customer. CNBC. Retrieved from https://www.cnbc.com/2017/06/16/amazons-acquisition-of-whole-foods-brings-in-a-microsoft-cloud-client.html

O'Hara, J. K., \& Benson, M. C. (2019). Where have all the direct-marketing farms gone? Patterns revealed from the 2017 census of agriculture. Journal of Agriculture, Food Systems, and Community Development, 9(1), 31-37. https://doi.org/10.5304/jafscd.2019.091.046

Oja Jay, D. (2018, October 15). Between BlackRock and a hard place: Is the industrial food chain unraveling... or rewinding? (Communique \#116). Retrieved from the ETC group website: https://www.etcgroup.org/content/between-blackrock-and-hard-place

Oreskovic, A. (2019, January 7). Amazon just became the world's most valuable company, ending Microsoft's spot at the top after 5 weeks. Business Insider. Retrieved from https://www.businessinsider.com/amazon-passes-microsoft-world-most-valuable-public-company-2019-1

Pappageorge, N. (2017, April 27). Amazon strategy teardown: Building new business pillars in AI, next-gen logistics, and enterprise cloud apps. LinkedIn. Retrieved from https://www.linkedin.com/pulse/amazon-strategy-teardown-building-new-business-ai-apps-pappageorge

Patel, R. (2007). Stuffed and starved: Markets, power and the bidden battle for the world's food system. Toronto: HarperCollins.

Shoot, B. (2018, June 11). Google gets into groceries by partnering with France's Carrefour for online food delivery. Fortune. Retrieved August 19, 2020, from https://fortune.com/2018/06/11/google-groceries-france-carrefour-online-food-delivery/

Solomon, D. B. (2018, September 13). Walmart's purchase of Mexico food delivery app set to spur e-commerce. Reuters. Retrieved from https://ca.reuters.com/article/technologyNews/idCAKCN1LT219-OCATC

Srnicek, N. (2017). The challenges of platform capitalism: Understanding the logic of a new business model. Juncture, 23(4), 254-257. https://doi.org/10.1111/newe.12023

Taylor, N. (2018, July 19). Amazon dominates online grocery share: Report. Winsight Grocery Business. Retrieved from https://www.winsightgrocerybusiness.com/retailers/amazon-dominates-online-grocery-share-report

U.S. Department of Agriculture (USDA). (2014, August). 2012 census of agriculture bighlights: Farmers marketing. Retrieved from USDA website: https://www.nass.usda.gov/Publications/Highlights/2014/Highlights Farmers Marketing.pdf

USDA. (2016, December). 2012 census of agriculture highlights: Direct farm sales of food, results from the 2015 food marketing practices survey. Retrieved from USDA website: https://www.nass.usda.gov/Publications/Highlights/2016/LocalFoodsMarketingPractices Highlights.pdf

U.S. Food and Drug Administration. (2018, March 28). What we do. Retrieved from https://www.fda.gov/about-fda/what-we-do\#mission 
Walmart. (2019, January 15). Top ways Walmart is changing how customers shop. Retrieved from https://corporate.walmart.com/newsroom/2019/01/15/top-ways-walmart-is-changing-how-customers-shop

Walmart Staff. (2017, October 3). Who is parcel? What this delivery company means to Walmart. Walmart. Retrieved from https:// corporate.walmart.com/newsroom/business/20171003/who-is-parcel-what-this-delivery-companymeans-to-walmart

White, T., \& King, S. (2019, April 11). 2017 census of agriculture data now available. U.S. Department of Agriculture. Retrieved from https://www.usda.gov/media/press-releases/2019/04/11/2017-census-agriculture-data-now-available

Whole Foods Market (WFM). (2017, August 24). Amazon and Whole Foods Market announce acquisition to close this Monday, will work together to make high-quality, natural and organic food affordable for everyone. Whole Foods Market Newsletter. Retrieved from https://media.wholefoodsmarket.com/news/amazon-and-whole-foods-marketannounce-acquisition-to-close-this-monday-wil

WFM. (2018a, February 20). Prime members now earn 5\% back when shopping at Whole Foods Market using the Amazon prime rewards visa card [Press release]. Whole Foods Market Newsroom. Retrieved from https://media.wholefoodsmarket.com/news/prime-members-now-earn-5-back-when-shopping-at-whole-foodsmarket-using-the

WFM. (2018b, November 13). Amazon and Whole Foods Market announce turkey deals for Thanksgiving. Whole Foods Market Newsletter. Retrieved from https://media.wholefoodsmarket.com/news/amazon-and-whole-foods-marketannounce-turkey-deals-for-thanksgiving

Williams, C. (2017, June 29). Online-to-door grocery deliveries will not upend the industry like e-commerce did brickand-mortar. Forbes. Retrieved from https://www.forbes.com/sites/bisnow/2017/06/29/online-to-door-grocerydeliveries-will-not-upend-the-industry-like-e-commerce-did-brick-and-mortar/\#1fab18f429ab

Winne, M. (2010). Food rebels, guerilla gardeners, and smart cookin' mamas: Fighting back in an age of industrial agriculture. Boston, MA: Beacon Press.

Winseck, D. R. (2016). Reconstructing the political economy of communication for the digital media age. The Political Economy of Communication, 4(2), 73-114. Retrieved from https://www.polecom.org/index.php/polecom/article/view/72

Wu, T. (2018). The cure of bigness: Antitrust in the new gilded age. New York: Columbia Global Reports. 